\title{
Factors associated with psychological distress among patients with breast cancer during the COVID-19 pandemic: a cross-sectional study in Wuhan, China
}

\author{
Xi Chen ${ }^{1} \cdot$ Longqiang Wang ${ }^{2} \cdot$ Lin $^{L_{i u}}{ }^{3} \cdot$ Ming Jiang $^{2} \cdot$ Weiming Wang ${ }^{1} \cdot$ Xiaorong Zhou $^{4} \cdot$ Jun Shao ${ }^{5}$ (I)
}

Received: 1 December 2020 / Accepted: 12 January 2021 / Published online: 1 February 2021

(C) The Author(s), under exclusive licence to Springer-Verlag GmbH, DE part of Springer Nature 2021

\begin{abstract}
Purpose This study aimed to examine the prevalence of psychological distress and the corresponding risk factors among patients with breast cancer affected by the outbreak of coronavirus disease 2019 (COVID-19).

Methods This cross-sectional, survey-based, region-stratified study was conducted from March 14 to March 21, 2020. An online survey was used to collect the basic characteristics of patients with breast cancer. The degree of depression, anxiety, and insomnia symptoms were assessed using the Patient Health Questionnaire (PHQ-9), the Generalized Anxiety Disorder (GAD-7), and the Insomnia Severity Index (ISI) questionnaires, respectively. Multivariate logistic analysis was performed to identify factors associated with psychological distress outcomes.

Results Among the 834 patients with breast cancer included in the study, the prevalence of depression, anxiety, and insomnia was $21.6 \%, 15.5 \%$, and $14.7 \%$, respectively. No statistically significant difference in the prevalence of these symptoms was observed between patients in Wuhan and those outside Wuhan. Multivariate logistic regression analyses revealed that comorbidity, living alone, deterioration of breast cancer, and affected treatment plan were risk factors for psychological distress including depression, anxiety, and insomnia. When stratified by location, living alone was associated with depression and insomnia only among patients in Wuhan, but not those outside Wuhan.

Conclusions This study shows an elevated prevalence of depression, anxiety, and insomnia among patients with breast cancer during part of the COVID-19 pandemic. Patients with comorbidity, living alone, deterioration of breast cancer, and whose treatment plan was affected should be paid more attention to prevent mental disorders.
\end{abstract}

Keywords COVID-19 $\cdot$ Breast cancer $\cdot$ Risk factors $\cdot$ Depression $\cdot$ Anxiety $\cdot$ Insomnia

Xi Chen, Longqiang Wang and Lin Liu contributed equally to this work.

Xiaorong Zhou

zxrmed@sina.com

Jun Shao

shaojun_x@sohu.com

1 Department of Nutrition and Food Hygiene, Hubei Key Laboratory of Food Nutrition and Safety, School of Public Health, Tongji Medical College, Huazhong University of Science and Technology, Wuhan 430030, Hubei, People's Republic of China

2 Department of Thyroid and Breast Surgery, the Central Hospital of Wuhan, Tongji Medical College, Huazhong University of Science and Technology, Wuhan430014, Hubei, People's Republic of China
3 Department of Laboratory Medicine, Wuhan Medical and Health Center for Women and Children, Tongji Medical College, Huazhong University of Science and Technology, Wuhan 430016, Hubei, People's Republic of China

4 Hubei Provincial Center for Disease Control and Prevention, Wuhan 430079, Hubei, People's Republic of China

5 Breast Cancer Department, Hubei Cancer Hospital, Tongji Medical College, Huazhong University of Science and Technology, Wuhan 430079, Hubei, People's Republic of China 


\section{Introduction}

Coronavirus disease 2019 (COVID-19) first emerged in Wuhan, Hubei Province, China, in December 2019 [1]. It rapidly spread to 212 countries or territories outside of China and was later declared an international public health emergency by the World Health Organization on March 11, 2020. Many individuals have been affected and developed symptoms of psychological distress due to COVID-19. Studies among various populations such as the general public $[2,3]$, healthcare workers [4], pregnant women [5], or children [6] have revealed higher scores of anxiety and depression compared to that before COVID-19.

Patients with cancer might be immunocompromised by the effects of antineoplastic therapy and more likely to experience mental disorders, which can reduce their quality of life [7]. Among all solid malignancies, the highest prevalence of mental disorders was reported to be observed in patients with breast cancer [8]. As in many other countries, breast cancer now is the most common type of cancer among Chinese women, and cases in China account for $12.2 \%$ of all newly diagnosed breast cancers worldwide [9]. Depression, anxiety, and insomnia are the three common symptoms of psychological distress during the treatment period among women with breast cancer [10-12], which have also been identified to be associated with substantial functional impairment and higher mortality among breast cancer patients $[13,14]$.

During the COVID-19 pandemic, most breast cancer patients may not have access to the healthcare system for anticancer therapy, monitoring, and preventive or supportive care due to fear for safety or traffic control $[15,16]$. To our knowledge, only one previous study conducted at the beginning of Wuhan lockdown demonstrated the prevalence of psychological distress and found poor general condition, treatment discontinuation, aggressive molecular subtypes, and metastatic breast cancer as risk factors associated with psychological distress among patients with breast cancer [17]. However, the study was based only in Wuhan and did not identify the differences of risk factors for psychological distress between Wuhan, the origin and epicenter of the pandemic in China, and the areas less affected outside Wuhan. Additionally, previous studies found living alone was associated with psychological distress [18], but whether it is still the main risk factor during pandemic remains unknown. Given the limitations, more evidence is needed for policymakers to address the specific risk factors related to mental disorders of patients with breast cancer during the COVID-19 pandemic and implement effective healthcare interventions for them.

The current study aimed to evaluate mental health status among patients with breast cancer by quantifying the magnitude of symptoms of depression, anxiety, and insomnia and identify factors associated with these symptoms. Also, participants from Wuhan City and other areas outside Wuhan were enrolled in this study to compare interregional differences.

\section{Methods}

\section{Study population}

We conducted an observational cross-sectional study to address our research objectives. All participants were recruited mainly from hospitals in the Hubei Province of China from March 14 to March 21, 2020. All the patients with breast cancer enrolled in the study were being under the treatment of surgery, chemotherapy, endocrine therapy, targeted therapy, radiotherapy, or reexamination. Samples were stratified by their geographic location (Wuhan, outside Wuhan). The required ethical approval was obtained from the institutional review board of hospitals. Informed consent was obtained from the participants. The questionnaire was filled out anonymously and the confidentiality of the information and privacy of the participants were protected throughout the study. The study was approved by the Ethics Review Committee of Hubei Cancer Hospital (No. LLHBCH2020LW-002).

\section{Data collection}

The data were collected using a self-administered questionnaire. The questionnaire was filled out online through the Wenjuanxing platform, a website used to collect questionnaires (https://www.wjx.cn/app/survey.aspx). A total of 834 individuals provided informed consent and submitted the questionnaires.

The demographic factors included age (years), educational level (elementary school, high school, and college or higher), location (Wuhan, outside Wuhan), menstrual status (menstruating, perimenopause, and postmenopause), marital status (single, married, divorced, and windowed), comorbidity (no, yes), and living alone (no, yes). Breast cancer-related factors included stage of breast cancer (early or middle, late stage), deterioration of breast cancer (no, not sure, yes), and affected treatment plan (no, yes). Among patients whose treatment plan was affected, information on duration of treatment interruption (2-4, 4-6, 6-8, $\geq 8$ weeks), reason for treatment interruption, and type of discontinued anticancer therapy were also collected.

\section{Psychological status}

Depression, anxiety, and insomnia were assessed using the Chinese translation of the Patient Health Questionnaire (PHQ-9), Generalized Anxiety Disorder Scale (GAD-7), and the Insomnia Severity Index (ISI), respectively [19]. The 
validity and reliability of these 3 Chinese version questionnaires have been previously proven [20-22]. The PHQ-9 is a 9-item screening instrument. Each of the 9 items received a score of $0-3$. Depression severity was classified into none ( 0 $4)$, mild (5-9), moderate (10-14), and severe (> 15). Depression was defined as a sum score of $\geq 10$. The GAD-7 scale consists of 7 items, and each item was scored from 0 to 3 . Scores of 5, 10, and 15 were established as the cutoff points for mild, moderate, and severe anxiety, respectively. Anxiety was defined as a sum score of $\geq 10$. ISI has 7 questions. Each of the 7 items received a score of $0-4$. The total score is interpreted as follows: none (0-7), mild (8-14), moderate insomnia (15-21), and severe insomnia (22-28). Insomnia was defined as a sum score of $\geq 15$.

Cronbach's $\alpha$ value was determined as an indicator to assess the internal consistency of the questionnaire. In this study, the Cronbach's $\alpha$ alpha value was $0.91,0.91$, and 0.94 for the Chinese version of PHQ-9, GAD-7, and ISI scale, respectively, which is generally regarded as acceptable.

\section{Statistical analyses}

The data were presented using frequencies and percentages for categorical variables. A Chi-square test was used to compare basic characteristics between participants living in Wuhan and outside Wuhan. The nonparametric Mann-Whitney U test and Kruskal-Wallis test were used to compare the severity of each symptom between 2 or more groups. To determine potential risk factors for symptoms of depression, anxiety, and insomnia in participants, multivariate logistic regression models were used to estimate odds ratios (ORs) and 95\% confidence intervals (CIs) adjusting for age, educational level, marital status, menstrual status, location, comorbidity, breast cancer stage, living alone, deterioration of breast cancer, and affected treatment plan. We also examined the associations stratified by location (Wuhan, outside Wuhan). Statistical analyses were performed using SAS Version 9.4 (SAS Institute Inc). All tests were 2-sided with a significance threshold of $5 \%$.

\section{Results}

Among the 834 patients with breast cancer who responded to the questionnaire, $44.8 \%(n=374)$ lived in Wuhan. Most participants were aged $\geq 46$ years $(65.1 \%, n=543)$, had an education level of high school $(51.0 \%, n=425)$, were married $(86 \%, n=717)$, and were postmenopausal $(47.6 \%, n=397)$. Additionally, $48.3 \%(n=403)$ of the patients experienced other diseases except for breast cancer. During the COVID19 pandemic, $5.9 \%(n=49)$ participants reported living alone. Of the patients, $90.8 \%(n=757)$ were at early/middle stage of breast cancer, $9.1 \%(n=76)$ reported deterioration of breast cancer, and $61.2 \%(n=510)$ were affected on treatment plan.
Among these 510 patients whose treatment plan was affected, most participants were affected for more than 8 weeks $(28.4 \%$, $n=145)$, the most common reason was traffic control $(57.3 \%$, $n=292$ ), and reexamination was the most common discontinued anticancer therapy $(40.8 \%, n=208)$. The proportion of participants who had depression, anxiety, and insomnia was $21.6 \%, 15.5 \%$, and $14.7 \%$, respectively (Table 1).

Compared to patients who lived in Wuhan, those living outside Wuhan were more likely to be lower educated, menstruating, and experiencing deterioration of breast cancer. No significant statistical differences were found in age, marital status, comorbidity, breast cancer stage, living alone, affected treatment plan, and symptoms of psychological distress between groups (Table 1).

For depression, there were $47.0 \%, 31.4 \%, 14.3 \%$, and $7.3 \%$ of the patients categorized into none, mild, moderate, and severe categories, respectively. For anxiety, there were $32.3 \%, 52.3 \%, 11.3 \%$, and $4.2 \%$ of the patients who reported none, mild, moderate, and severe status, respectively. For insomnia, $50.5 \%, 34.9 \%, 11.6 \%$, and $3.4 \%$ of the patients experienced none, mild, moderate, and severe insomnia, respectively. The prevalence of depression, anxiety, and insomnia was $20.6 \%, 15.5 \%$, and $14.7 \%$, respectively. Compared with those who lived outside Wuhan, patients living in Wuhan were more likely to report severe symptoms of anxiety and insomnia, but not depression. Compared with patients without comorbidity, those who had comorbidity reported experiencing more severe symptoms of depression and insomnia, but not anxiety. Patients who were at late stage of breast cancer were more likely to experience severe symptoms of anxiety compared to those at early/middle stage. Patients who lived alone, had deterioration of breast cancer, and whose treatment plan was affected reported experiencing more severe symptom levels of depression, anxiety, and insomnia (Table 2).

In the multivariate analysis, comorbidity, living alone, and deterioration of breast cancer were independently associated with a higher risk of all the three symptoms of depression, anxiety, and insomnia in total participants after adjustment for potential confounders (comorbidity: depression, OR, 1.48, 95\% CI, 1.03, 2.11; anxiety, OR, 1.58, 95\% CI, 1.05, 2.37; insomnia, OR, 1.80, 95\% CI, 1.19, 2.72; living alone: depression, OR, 2.66, 95\% CI, 1.36, 5.22; anxiety, OR, 3.86, 95\% CI, 1.90, 7.86; insomnia, OR, 2.78, 95\% CI, 1.32, 5.83; deterioration of breast cancer: depression, OR, 7.41, 95\% CI, 4.03, 13.61; anxiety, OR, 5.98, 95\% CI, 3.07, 11.67; insomnia, OR, 4.35, 95\% CI, 2.18, 8.70). Affected treatment plan was independently associated with depression and anxiety (depression, OR, 1.20, 95\% CI, 1.81, 1.79; anxiety, OR, 1.68, 95\% CI, 1.04, 2.70), but not insomnia (Table 3).

When stratified by location (Wuhan, outside Wuhan), significant associations of living alone with depression and insomnia were observed only among patients in Wuhan, but not in those outside Wuhan. The association between living alone 
Table 1 Basic characteristics and psychological distress of the patients with breast cancer in Wuhan versus those outside Wuhan

\begin{tabular}{|c|c|c|c|c|}
\hline & & Location & & \\
\hline Characteristics & Total $(n=834)$ & Wuhan $(n=374)$ & Outside Wuhan $(n=460)$ & $P$ \\
\hline \multicolumn{5}{|l|}{ Basic characteristics } \\
\hline Age (years) & & & & 0.422 \\
\hline$<46$ & $291(34.9)$ & $125(33.4)$ & $166(36.1)$ & \\
\hline$\geq 46$ & $543(65.1)$ & $249(66.6)$ & $294(63.9)$ & \\
\hline Educational level & & & & 0.001 \\
\hline Junior school or lower & $96(11.5)$ & $33(8.8)$ & $63(13.7)$ & \\
\hline High school & $425(51.0)$ & $176(47.1)$ & $249(54.1)$ & \\
\hline College or higher & $313(37.5)$ & $165(44.1)$ & $148(32.2)$ & \\
\hline Marital status & & & & 0.131 \\
\hline Married & $717(86.0)$ & $314(84.0)$ & $403(87.6)$ & \\
\hline Single/divorced/windowed & $117(14.0)$ & $60(16.0)$ & $57(12.4)$ & \\
\hline Menstrual status & & & & $<0.001$ \\
\hline Menstruating & $281(33.7)$ & $113(30.2)$ & $168(36.5)$ & \\
\hline Perimenopausal & $156(18.7)$ & $55(14.7)$ & $101(22.0)$ & \\
\hline Postmenopause & $397(47.6)$ & $206(55.1)$ & $191(41.5)$ & \\
\hline Comorbidity & & & & 0.196 \\
\hline No & $431(51.7)$ & $184(49.2)$ & $247(53.7)$ & \\
\hline Yes & $403(48.3)$ & $190(50.8)$ & $213(46.3)$ & \\
\hline Living alone & & & & 0.549 \\
\hline No & 785 (94.6) & $350(93.6)$ & 435 (94.6) & \\
\hline Yes & $49(5.9)$ & $24(6.4)$ & $25(5.4)$ & \\
\hline Stage of breast cancer & & & & 0.724 \\
\hline Early or middle stage & $757(90.8)$ & $338(90.4)$ & $419(91.9)$ & \\
\hline Late stage & $77(9.2)$ & $36(9.6)$ & $41(8.9)$ & \\
\hline Deterioration of breast cancer & & & & 0.013 \\
\hline No & $359(43.0)$ & $145(38.8)$ & $214(46.5)$ & \\
\hline Not sure & $399(47.8)$ & $200(53.5)$ & $199(43.3)$ & \\
\hline Yes & $76(9.1)$ & $29(7.8)$ & $47(10.2)$ & \\
\hline Affected treatment plan & & & & 0.369 \\
\hline No & $324(38.8)$ & $139(37.2)$ & $185(40.2)$ & \\
\hline Yes & $510(61.2)$ & $235(62.8)$ & $275(59.8)$ & \\
\hline Duration of treatment interruption ${ }^{\mathrm{a}}$ & & & & 0.019 \\
\hline $2-4$ weeks & $89(17.5)$ & $40(17.0)$ & $49(17.8)$ & \\
\hline 4-6 weeks & $98(19.2)$ & $59(25.1)$ & $39(14.2)$ & \\
\hline $6-8$ weeks & $101(19.8)$ & $48(20.4)$ & $53(19.3)$ & \\
\hline$\geq 8$ weeks & $145(28.4)$ & $58(24.7)$ & $87(31.6)$ & \\
\hline Not sure & $77(15.1)$ & $30(12.8)$ & $47(17.1)$ & \\
\hline Reason for treatment interruption ${ }^{\mathrm{a}}$ & & & & 0.004 \\
\hline Traffic control & $292(57.3)$ & $117(49.8)$ & $175(63.6)$ & \\
\hline No hospital beds or appointment hours & $66(12.9)$ & $42(17.9)$ & $24(8.7)$ & \\
\hline Fear of infection & $134(26.3)$ & $67(28.5)$ & $67(24.4)$ & \\
\hline Personal other reasons & $18(3.5)$ & $9(3.8)$ & $9(3.3)$ & \\
\hline Discontinued anticancer therapy ${ }^{\mathrm{a}}$ & & & & 0.105 \\
\hline Delayed surgery & $44(8.6)$ & $17(7.2)$ & $27(9.8)$ & \\
\hline Chemotherapy after surgery & $101(19.8)$ & $43(18.3)$ & $58(21.1)$ & \\
\hline Endocrine therapy after surgery & $77(15.1)$ & $46(19.6)$ & $31(11.3)$ & \\
\hline Targeted therapy after surgery & $65(12.7)$ & $30(12.8)$ & $35(12.7)$ & \\
\hline Radiotherapy after surgery & $15(2.9)$ & $9(3.8)$ & $6(2.2)$ & \\
\hline
\end{tabular}


Table 1 (continued)

\begin{tabular}{llll}
\hline & \multicolumn{3}{c}{ Location } \\
\hline $\begin{array}{l}\text { Reexamination } \\
\text { Psychological distress }\end{array}$ & $208(40.8)$ & $90(38.3)$ & $118(42.9)$ \\
$\begin{array}{l}\text { Depression } \\
\text { No }\end{array}$ & $654(78.4)$ & $288(77.0)$ & \\
Yes & $180(21.6)$ & $86(23.0)$ & $366(79.6)$ \\
Anxiety & & & $94(20.6)$ \\
No & $705(84.5)$ & $308(82.4)$ & $397(86.3)$ \\
Yes & $129(15.5)$ & $66(17.6)$ & $63(13.7)$ \\
Insomnia & $711(85.3)$ & $311(83.2)$ & $400(87.0)$ \\
No & $123(14.7)$ & $63(16.8)$ & $60(13.0)$ \\
Yes & & & 0.117 \\
\hline
\end{tabular}

Data are presented as number $(\%)$

Percentages are weighted to account for the sample size, $n=834$

${ }^{\text {a }}$ Percentages are weighted to the size of the group of patients whose treatment plan was affected, $n=510$

and anxiety was observed among both patients in Wuhan and those outside Wuhan. The associations between deterioration of breast cancer and the three symptoms of psychological distress were statistically significant among both patients in Wuhan and those outside Wuhan (Table 3).

\section{Discussion}

The present cross-sectional epidemiological study revealed that the prevalence of depression, anxiety, and insomnia symptoms in patients with breast cancer in China during part of the COVID-19 epidemic period was $21.6 \%, 15.5 \%$, and $14.7 \%$, respectively. After adjustment for potential confounders, comorbidity, late stage, living alone, deterioration of breast cancer, and affected treatment plan were independent risk factors for depression, anxiety, and insomnia. Additionally, living alone was associated with depression and insomnia only among patients in Wuhan, but not those outside Wuhan.

According to a meta-analysis of 72 studies performed in 30 countries, the global prevalence of depression among breast cancer patients was $32.2 \%$, and the prevalence of depression was different across countries [23]. In a Chinese pre-COVID19 cohort study, depression was estimated to affect $12.6 \%$ of patients with breast cancer, which is lower than that in our study [24]. However, two previous studies conducted in China before the pandemic showed similar prevalence of depression of $23.7 \%$ and $20.6 \%$ among patients with breast cancer to that of our study $[18,25]$. Elevated symptom of anxiety was observed in our study compared to that of a previous Chinese study where $8.8 \%$ of patients with breast cancer reported experiencing anxiety [18]. One British study conducted before the COVID-19 pandemic revealed that the prevalence of insomnia was $8 \%$ before diagnosis, and $18 \%$ after the breast cancer diagnosis, which is consistent with that of our study [26]. However, few studies reported the prevalence of psychological distress among patients with breast cancer during the COVID-19 pandemic. To our knowledge, there is only one survey of Chinese residents early in the COVID-19 outbreak (February 16-19, 2020), 22.1\% of respondents reported moderate or severe depression, $21.4 \%$ reporting moderate or severe anxiety, and $16.8 \%$ reporting moderate to severe insomnia [17]. The prevalence of depressive, anxiety, and insomnia symptoms in our study is slightly lower, suggesting that the psychological impact of pandemic control may be of benefit for patients with breast cancer. Due to the limited evidence, more studies are warranted in the future to evaluate the prevalence of psychological distress during the COVID-19 pandemic among patients with breast cancer.

Consistent with previous studies, we confirmed several risk factors for psychological distress such as comorbidity and living alone $[17,18,24]$. Breast cancer patients with comorbidity are more likely to have worse outcomes such as higher death rates compared to those without comorbidity [27, 28]. Therefore, they faced more stress which may lead to elevated symptoms of psychological distress. Living alone increases the risk of social isolation. Individuals who are socially isolated receive significantly less emotional and family support, which in turn increases the risk of depression [29]. During the pandemic, it is a hard time for patients to maintain a social relationship with friends and doctors due to lockdown. More attention should be paid on those patients with comorbidity and living alone to prevent the symptoms of mental disorders.

In addition to the well-documented risk factors, due to the COVID-19 pandemic, deterioration of breast cancer and 


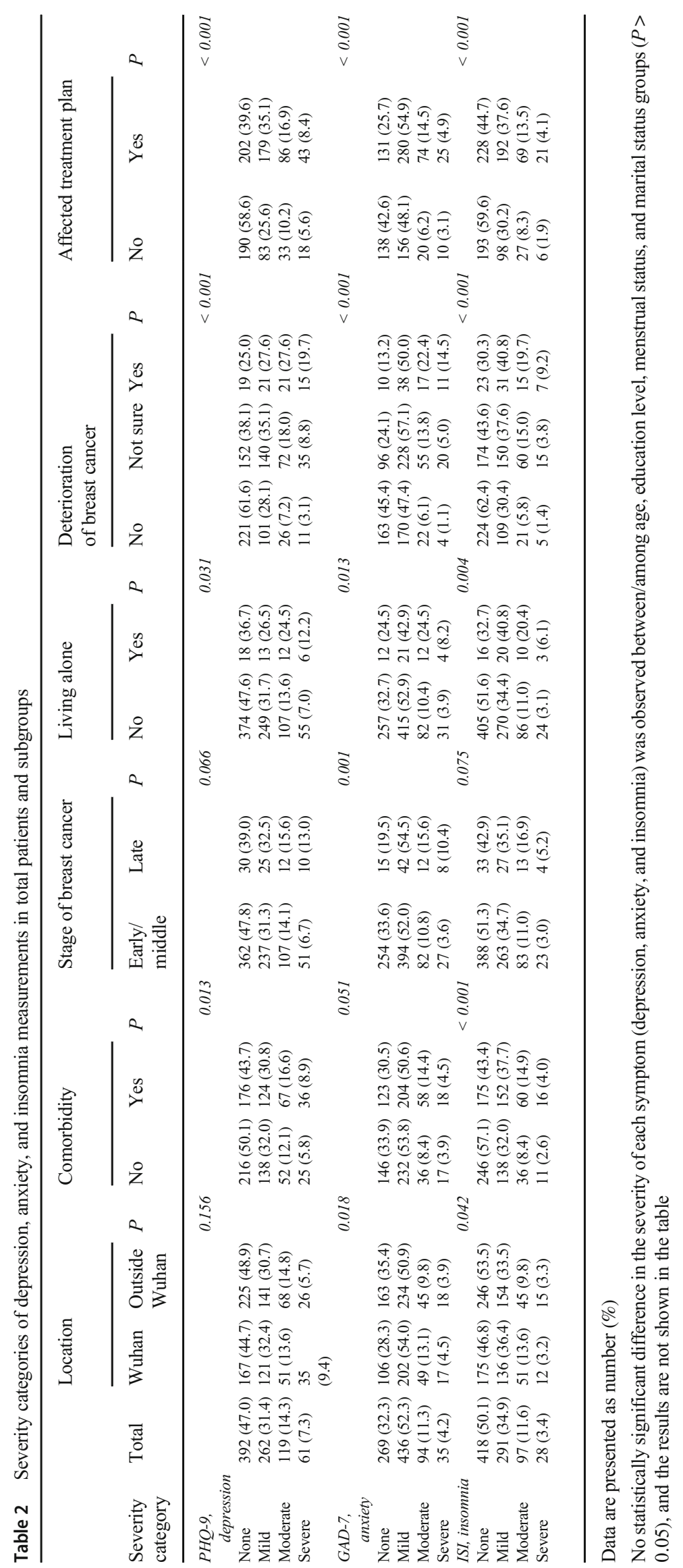


Table 3 Risk factors for depression, anxiety, and insomnia identified by multivariable logistic regression analysis

\begin{tabular}{|c|c|c|c|c|c|c|}
\hline & Total & & $\begin{array}{l}\text { Location } \\
\text { Wuhan }\end{array}$ & & Outside Wuhan & \\
\hline & Cases/total (\%) & OR $(95 \% C I)^{a}$ & Cases/total (\%) & OR $(95 \% C I)^{b}$ & Cases/total (\%) & OR $(95 \% C I)^{b}$ \\
\hline \multicolumn{7}{|c|}{ Depression } \\
\hline \multicolumn{7}{|c|}{ Comorbidity } \\
\hline No & $77 / 431(17.9)$ & Ref & 32/184 (17.4) & Ref & 45/247 (18.2) & Ref \\
\hline Yes & $103 / 403(25.9)$ & $1.48(1.03,2.11)$ & $54 / 190(28.4)$ & $1.65(0.95,2.87)$ & 49/213 (23.0) & $1.36(0.84,2.2)$ \\
\hline \multicolumn{7}{|c|}{ Living alone } \\
\hline No & $162 / 785(20.6)$ & Ref & $74 / 350(21.1)$ & Ref & $88 / 435(20.2)$ & Ref \\
\hline Yes & $18 / 49(36.7)$ & $2.66(1.36,5.22)$ & $12 / 24(50.0)$ & $5.50(2.11,14.36)$ & $6 / 25(24.0)$ & $1.34(0.47,3.78)$ \\
\hline \multicolumn{7}{|c|}{ Deterioration of breast cancer } \\
\hline No & $37 / 359(10.3)$ & Ref & $14 / 145(9.7)$ & Ref & 23/214 (10.7) & Ref \\
\hline Not sure & $107 / 399(26.8)$ & $3.06(2.00,4.70)$ & $54 / 200(27.0)$ & $3.24(1.65,6.35)$ & $53 / 199(26.6)$ & $3.14(1.77,5.56)$ \\
\hline Yes & $36 / 76(47.4)$ & $7.41(4.03,13.61)$ & $18 / 29(62.1)$ & $14.6(5.3,40.17)$ & $18 / 47(38.8)$ & $5.07(2.29,11.21)$ \\
\hline \multicolumn{7}{|c|}{ Affected treatment plan } \\
\hline No & $51 / 324(15.7)$ & Ref & $22 / 139(15.8)$ & Ref & 29/185 (15.7) & Ref \\
\hline Yes & $129 / 510(25.3)$ & $1.20(1.81,1.79)$ & $64 / 235(27.2)$ & $1.50(0.81,2.77)$ & $65 / 275(23.6)$ & $1.05(0.61,1.82)$ \\
\hline \multicolumn{7}{|l|}{ Anxiety } \\
\hline \multicolumn{7}{|c|}{ Comorbidity } \\
\hline No & $53 / 431(12.3)$ & Ref & 24/184 (13.0) & Ref & 29/247 (11.7) & Ref \\
\hline Yes & 76/403 (18.9) & $1.58(1.05,2.37)$ & $42 / 190(22.1)$ & $1.8(0.99,3.27)$ & $34 / 213(16.0)$ & $1.39(0.78,2.49)$ \\
\hline \multicolumn{7}{|c|}{ Living alone } \\
\hline No & $113 / 785(14.4)$ & Ref & $57 / 350(16.3)$ & Ref & $56 / 435(12.9)$ & Ref \\
\hline Yes & $16 / 49(32.7)$ & $3.86(1.90,7.86)$ & $9 / 24(37.5)$ & $4.44(1.63,12.06)$ & $7 / 25(28.0)$ & $3.80(1.31,11.03)$ \\
\hline \multicolumn{7}{|c|}{ Deterioration of breast cancer } \\
\hline No & $26 / 359(7.2)$ & Ref & $13 / 145(9.0)$ & Ref & $13 / 214(6.1)$ & Ref \\
\hline Not sure & 75/399 (18.8) & $2.52(1.53,4.14)$ & $41 / 200(20.5)$ & $2.26(1.12,4.57)$ & $34 / 199(17.1)$ & $3.10(1.50,6.40)$ \\
\hline Yes & $28 / 76(36.8)$ & $5.98(3.07,11.66)$ & $12 / 29(41.4)$ & $5.28(1.9,14.7)$ & $16 / 47(34.0)$ & $6.54(2.62,16.29)$ \\
\hline \multicolumn{7}{|c|}{ Affected treatment plan } \\
\hline No & $30 / 324(9.3)$ & Ref & 15/139 (10.8) & Ref & $15 / 185(8.1)$ & ref \\
\hline Yes & 99/510 (19.4) & $1.68(1.04,2.70)$ & $51 / 235(21.7)$ & $1.83(0.93,3.64)$ & 48/275 (17.5) & $1.44(0.72,2.89)$ \\
\hline \multicolumn{7}{|l|}{ Insomnia } \\
\hline \multicolumn{7}{|c|}{ Comorbidity } \\
\hline No & 47/431 (10.9) & Ref & $16 / 184(8.7)$ & Ref & $31 / 247(12.6)$ & Ref \\
\hline Yes & 76/403 (18.9) & $1.80(1.19,2.72)$ & $47 / 190(24.7)$ & $3.34(1.73,6.43)$ & 29/213 (13.6) & $1.1(0.62,1.96)$ \\
\hline \multicolumn{7}{|c|}{ Living alone } \\
\hline No & $110 / 785(14.0)$ & Ref & $54 / 350(15.4)$ & Ref & $56 / 435(12.9)$ & Ref \\
\hline Yes & $13 / 49(26.5)$ & $2.78(1.32,5.83)$ & $9 / 24(37.5)$ & $4.99(1.79,13.92)$ & $4 / 25(16.0)$ & $1.69(0.5,5.66)$ \\
\hline \multicolumn{7}{|c|}{ Deterioration of breast cancer } \\
\hline No & $26 / 359(7.2)$ & Ref & $10 / 145(6.9)$ & Ref & $16 / 214(7.5)$ & Ref \\
\hline Not sure & 75/399 (18.8) & $2.67(1.62,4.38)$ & $42 / 200(21.0)$ & $3.28(1.51,7.13)$ & 33/199 (16.6) & $2.35(1.19,4.65)$ \\
\hline Yes & $22 / 76(28.9)$ & $4.35(2.18,8.70)$ & $11 / 29(37.9)$ & $6.90(2.31,20.63)$ & $11 / 47(23.4)$ & $2.9(1.15,7.33)$ \\
\hline \multicolumn{7}{|c|}{ Affected treatment plan } \\
\hline No & $33 / 324(10.2)$ & Ref & $17 / 139(12.2)$ & Ref & $16 / 185(8.6)$ & Ref \\
\hline Yes & $90 / 510(17.6)$ & $1.36(0.85,2.17)$ & 46/235 (19.6) & $1.28(0.64,2.57)$ & $44 / 275(16.0)$ & $1.46(0.74,2.88)$ \\
\hline
\end{tabular}

${ }^{\text {a }}$ Multivariate analyses were adjusted for age, educational level, marital status, menstrual status, location, comorbidity, stage of breast cancer, living alone, deterioration of breast cancer, and affected treatment plan. Factors including location, age, educational level, menstrual status, marital status, and stage of breast cancer are not significantly associated with psychological distress symptoms and not shown in the table

${ }^{\mathrm{b}}$ Multivariate analyses were adjusted for all the covariates included in the total population except location 
affected treatment plan were reported by most patients. To our knowledge, these two issues were firstly reported to be risk factors for psychological distress. During the COVID-19 pandemic, China implemented measures to limit the spread of the virus, such as traffic control [30], which was the most common reason for discontinued therapy in our study. Besides, many patients chose to stay at home instead of visiting doctors because of fear for their safety. Therefore, when the pandemic is under control, psychologists and social groups need to provide support to patients whose breast cancer was deteriorated and treatment plan was affected during the COVID-19 outbreak to reduce mental health problems.

Subgroups analyses found that the mental health status of patients in Wuhan was more likely to be affected by living alone compared to those outside Wuhan. When faced with the same situation of COVID-19, patients in Wuhan might worry about more problems such as shortage of food supply. Living alone may exacerbate this negative emotion without support from family members as well as friends. The imposed lockdown resulted in travel restrictions to and from Wuhan to ensure rigorous adherence to home quarantine. Social distancing was practiced by canceling events and gatherings and closing public places as well as schools and universities [16]. Our results suggested that the interventions for the mental health of patients who lived alone should be a priority during any public wide epidemic, especially in epicenters during a pandemic such as Wuhan in China.

This study has several limitations. Firstly, this is a crosssectional study. Previous studies demonstrated that depression, anxiety, and insomnia changed during intermittent periods between chemotherapy sessions [31,32]. Longitudinal studies should be conducted in the future. Besides, due to the lack of data from general people, we cannot distinguish specific risk factors for mental health outcomes among patients with breast cancer. What's more, we did not explore the factors associated with a lower risk of psychological distress. Further studies addressing the protective factors for mental health status among patients with breast cancer were warranted.

\section{Conclusions}

Our study presents the prevalence of depression, anxiety, and insomnia in patients with breast cancer during the part of the COVID-19 pandemic. Meanwhile, the associated factors were identified, indicating that awareness of the increased risk of psychological distress in patients with comorbidity, living alone, reporting deterioration of breast cancer, and whose treatment plan was affected. Our results emphasize the importance of implementing effective interventions for screening high-risk patients with breast cancer for mental disorders during routine treatment and follow-ups after the COVID-19 pandemic. Furthermore, psychological support should be offered to mitigate the negative emotional sequelae of breast cancer.

Acknowledgments The authors thank all the participants and staff in the study for their valuable contributions.

Authors' contributions JS and XZ conceived the study conception. All authors conducted the survey and collected data. XC, LW, and LL contributed equally to the study design. XC performed the statistical analysis and wrote the manuscript. LW and LL participated in the discussions concerning the interpretation of results and revision of the manuscript. $\mathrm{MJ}$ contributed to get the resources. All authors commented on previous versions of the manuscript. All authors read and approved the final manuscript.

Funding This work was supported by Research Funds for the Prevention and Control of COVID-19 Pandemic in Wuhan (EX20E17).

Data availability The datasets generated and/or analyzed during the current study are available from the corresponding author on reasonable request.

\section{Compliance with ethical standards}

Conflict of interest All authors declare no competing interest.

Ethics approval The study was approved by the Ethics Review Committee of Hubei Cancer Hospital (No. LLHBCH2020LW-002).

Consent to participate Informed consent was obtained from the participants.

Consent for publication Informed consent for publication was obtained from the authors.

Code availability The code used in the current study is available from the corresponding author on reasonable request.

\section{References}

1. Huang C, Wang Y, Li X, Ren L, Zhao J, Hu Y, Zhang L, Fan G, Xu J, Gu X, Cheng Z, Yu T, Xia J, Wei Y, Wu W, Xie X, Yin W, Li H, Liu M, Xiao Y, Gao H, Guo L, Xie J, Wang G, Jiang R, Gao Z, Jin Q, Wang J, Cao B (2020) Clinical features of patients infected with 2019 novel coronavirus in Wuhan, China. Lancet 395(10223):497506

2. Shi L, Lu ZA, Que JY, Huang XL, Liu L, Ran MS, Gong YM, Yuan K, Yan W, Sun YK, Shi J, Bao YP, Lu L (2020) Prevalence of and risk factors associated with mental health symptoms among the general population in China during the coronavirus disease 2019 pandemic. JAMA Netw Open 3(7):e2014053

3. Vindegaard N, Benros ME (2020) COVID-19 pandemic and mental health consequences: systematic review of the current evidence. Brain Behav Immun 89:531-542

4. Rossi R, Socci V, Pacitti F, di Lorenzo G, di Marco A, Siracusano A, Rossi A (2020) Mental health outcomes among frontline and second-line health care workers during the coronavirus disease 2019 (COVID-19) pandemic in Italy. JAMA Netw Open 3(5): e2010185 
5. Wu Y, Zhang C, Liu H et al (2020) Perinatal depressive and anxiety symptoms of pregnant women during the coronavirus disease 2019 outbreak in China. Am J Obstet Gynecol 223(2):240.e1-240.e9.

6. Song R (2020) Mental health status among children in home confinement during the coronavirus disease 2019 outbreak in Hubei Province, China. JAMA Pediatr 174(9):898-900

7. Kuderer NM, Choueiri TK, Shah DP, Shyr Y, Rubinstein SM, Rivera DR, Shete S, Hsu CY, Desai A, de Lima Lopes G Jr, Grivas P, Painter CA, Peters S, Thompson MA, Bakouny Z, Batist G, Bekaii-Saab T, Bilen MA, Bouganim N, Larroya MB, Castellano D, del Prete SA, Doroshow DB, Egan PC, Elkrief A, Farmakiotis D, Flora D, Galsky MD, Glover MJ, Griffiths EA, Gulati AP, Gupta S, Hafez N, Halfdanarson TR, Hawley JE, Hsu E, Kasi A, Khaki AR, Lemmon CA, Lewis C, Logan B, Masters T, McKay RR, Mesa RA, Morgans AK, Mulcahy MF, Panagiotou OA, Peddi P, Pennell NA, Reynolds K, Rosen LR, Rosovsky R, Salazar M, Schmidt A, Shah SA, Shaya JA, Steinharter J, StockerlGoldstein KE, Subbiah S, Vinh DC, Wehbe FH, Weissmann LB, Wu JTY, Wulff-Burchfield E, Xie Z, Yeh A, Yu PP, Zhou AY, Zubiri L, Mishra S, Lyman GH, Rini BI, Warner JL, Abidi M, Acoba JD, Agarwal N, Ahmad S, Ajmera A, Altman J, Angevine AH, Azad N, Bar MH, Bardia A, Barnholtz-Sloan J, Barrow B, Bashir B, Belenkaya R, Berg S, Bernicker EH, Bestvina C, Bishnoi R, Boland G, Bonnen M, Bouchard G, Bowles DW, Busser F, Cabal A, Caimi P, Carducci T, Casulo C, Chen JL, Clement JM, Chism D, Cook E, Curran C, Daher A, Dailey M, Dahiya S, Deeken J, Demetri GD, DiLullo S, Duma N, Elias R, Faller B, Fecher LA, Feldman LE, Friese CR, Fu P, Fu J, Futreal A, Gainor J, Garcia J, Gill DM, Gillaspie EA, Giordano A, Glace (M)G, Grothey A, Gulati S, Gurley M, Halmos B, Herbst R, Hershman D, Hoskins K, Jain RK, Jabbour S, Jha A, Johnson DB, Joshi M, Kelleher K, Kharofa J, Khan H, Knoble J, Koshkin VS, Kulkarni AA, Lammers PE, Leighton JC Jr, Lewis MA, Li X, Li A, Lo KMS, Loaiza-Bonilla A, LoRusso P, Low CA, Lustberg MB, Mahadevan D, Mansoor AH, Marcum M, Markham MJ, Handy Marshall C, Mashru SH, Matar S, McNair C, McWeeney S, Mehnert JM, Menendez A, Menon H, Messmer M, Monahan R, Mushtaq S, Nagaraj G, Nagle S, Naidoo J, Nakayama JM, Narayan V, Nelson HH, Nemecek ER, Nguyen R, Nuzzo PV, Oberstein PE, Olszewski AJ, Owenby S, Pasquinelli MM, Philip J, Prabhakaran S, Puc M, Ramirez A, Rathmann J, Revankar SG, Rho YS, Rhodes TD, Rice RL, Riely GJ, Riess J, Rink C, Robilotti EV, Rosenstein L, Routy B, Rovito MA, Saif MW, Sanyal A, Schapira L, Schwartz C, Serrano O, Shah M, Shah C, Shaw G, Shergill A, Shouse G, Soares HP, Solorzano CC, Srivastava PK, Stauffer K, Stover DG, Stratton J, Stratton C, Subbiah V, Tamimi R, Tannir NM, Topaloglu U, van Allen E, van Loon S, Vega-Luna K, Venepalli N, Verma AK, Vikas P, Wall S, Weinstein PL, Weiss M, WiseDraper T, Wood WA, Xu W(V), Yackzan S, Zacks R, Zhang T, Zimmer AJ, West J (2020) Clinical impact of COVID-19 on patients with cancer (CCC19): a cohort study. Lancet 395(10241): 1907-1918

8. Mehnert A, Brahler E, Faller H et al (2014) Four-week prevalence of mental disorders in patients with cancer across major tumor entities. J Clin Oncol 32(31):3540-3546

9. Fan L, Strasser-Weippl K, Li JJ, St Louis J, Finkelstein DM, Yu KD, Chen WQ, Shao ZM, Goss PE (2014) Breast cancer in China. Lancet Oncol 2014 15(7):e279-e289

10. Burgess C, Cornelius V, Love S, Graham J, Richards M, Ramirez A (2005) Depression and anxiety in women with early breast cancer: five year observational cohort study. BMJ 330(7493):702

11. Kang JI, Sung NY, Park SJ, Lee CG, Lee BO (2014) The epidemiology of psychiatric disorders among women with breast cancer in South Korea: analysis of national registry data. Psychooncology 23(1):35-39
12. Savard J, Simard S, Blanchet J, Ivers H, Morin CM (2001) Prevalence, clinical characteristics, and risk factors for insomnia in the context of breast cancer. Sleep 24(5):583-590

13. Yang YL, Liu L, Wang XX, Wang Y, Wang L (2014) Prevalence and associated positive psychological variables of depression and anxiety among Chinese cervical cancer patients: a cross-sectional study. PLoS One 9(4):e94804

14. Mustafa M, Carson-Stevens A, Gillespie D et al (2013) Psychological interventions for women with metastatic breast cancer. Cochrane Database Syst Rev 6:CD004253

15. Yuan Z, Xiao Y, Dai Z, Huang J, Zhang Z, Chen Y (2020) Modelling the effects of Wuhan's lockdown during COVID-19, China. Bull WHO 98(7):484-494

16. Lau H, Khosrawipour V, Kocbach P et al (2020) The positive impact of lockdown in Wuhan on containing the COVID-19 outbreak in China. J Travel Med 27(3):taaa037.

17. Juanjuan L, Santa-Maria CA, Hongfang F, Lingcheng W, Pengcheng Z, Yuanbing X, Yuyan T, Zhongchun L, Bo D, Meng L, Qingfeng Y, Feng Y, Yi T, Shengrong S, Xingrui L, Chuang C (2020) Patient-reported outcomes of patients with breast cancer during the COVID-19 outbreak in the epicenter of China: a crosssectional survey study. Clin Breast Cancer 20(5):e651-e662

18. Lan B, Jiang S, Li T, Sun X, Ma F (2020) Depression, anxiety, and their associated factors among Chinese early breast cancer in women under 35 years of age: a cross sectional study. Curr Probl Cancer 44(5): 100558

19. Andersen BL, DeRubeis RJ, Berman BS, Gruman J, Champion VL, Massie MJ, Holland JC, Partridge AH, Bak K, Somerfield MR, Rowland JH, American Society of Clinical Oncology (2014) Screening, assessment, and care of anxiety and depressive symptoms in adults with cancer: an American Society of Clinical Oncology guideline adaptation. J Clin Oncol 32(15):1605-1619

20. Zeng QZHY, Liu H et al (2013) Patient-reported outcomes of patients with breast cancer during the COVID-19 outbreak in the epicenter of China: a cross-sectional survey study. Chin Mental Health J 27:163-168

21. Feng Xia YX, HuiLing S, Yu B et al (2019) Evaluation of reliability and validity of the Patient Health Questionnaire-9 in patients with acne. Chin J Dermatol 52(7):461-466

22. Yu DS (2010) Insomnia Severity Index: psychometric properties with Chinese community-dwelling older people. J Adv Nursing 66(10):2350-2359

23. Pilevarzadeh M, Amirshahi M, Afsargharehbagh R, Rafiemanesh H, Hashemi SM, Balouchi A (2019) Global prevalence of depression among breast cancer patients: a systematic review and metaanalysis. Breast Cancer Res Treat 176(3):519-533

24. Chen X, Zheng Y, Zheng W, Gu K, Chen Z, Lu W, Shu XO (2009) Prevalence of depression and its related factors among Chinese women with breast cancer. Acta Oncol 48(8):1128-1136

25. Qiu J, Yang M, Chen W, Gao X, Liu S, Shi S, Xie B (2012) Prevalence and correlates of major depressive disorder in breast cancer survivors in Shanghai, China. Psychooncology 21(12): 1331-1337

26. Fleming L, Randell K, Stewart E et al (2019) Insomnia in breast cancer: a prospective observational study. Sleep 42(3):zsy245.

27. Kiderlen M, de Glas NA, Bastiaannet E, van de Water W, de Craen AJM, Guicherit OR, Merkus JWS, Extermann M, van de Velde CJH, Liefers GJ (2014) Impact of comorbidity on outcome of older breast cancer patients: a FOCUS cohort study. Breast Cancer Res Treat 145(1):185-192

28. Webster S, Lawn S, Chan R, Koczwara B (2020) The role of comorbidity assessment in guiding treatment decision-making for women with early breast cancer: a systematic literature review. Support Care Cancer 28(3):1041-1050 
29. Cacioppo JT, Hawkley LC (2003) Social isolation and health, with an emphasis on underlying mechanisms. Perspect Biol Med 46(3 Suppl):S39-S52

30. Chinazzi M, Davis JT, Ajelli M, Gioannini C, Litvinova M, Merler S, Pastore y Piontti A, Mu K, Rossi L, Sun K, Viboud C, Xiong X, Yu H, Halloran ME, Longini IM Jr, Vespignani A (2020) The effect of travel restrictions on the spread of the 2019 novel coronavirus (COVID-19) outbreak. Science 368(6489):395-400

31. Zhang J, Zhou Y, Feng Z, Xu Y, Zeng G (2018) Longitudinal trends in anxiety, depression, and quality of life during different intermittent periods of adjuvant breast cancer chemotherapy. Cancer Nurs 41(1):62-68

32. Zhao Y, Liu JE, Lewis FM, Nie ZH, Qiu H, Han J, Su YL, Yang SS (2020) Effects of mindfulness-based cognitive therapy on breast cancer survivors with insomnia: a randomised controlled trial. Eur J Cancer Care (Engl) 29(5):e13259

Publisher's note Springer Nature remains neutral with regard to jurisdictional claims in published maps and institutional affiliations. 